\title{
Coupled Coincidence Point and Coupled Fixed Point Theorems via Generalized Meir-Keeler Type Contractions
}

\author{
Hassen Aydi, ${ }^{1}$ Erdal Karapınar, $^{2}$ and İnci M. Erhan ${ }^{2}$ \\ ${ }^{1}$ Institut Supérieur d'Informatique et des Technologies de Communication de Hammam Sousse, \\ Université de Sousse, Route GP1, 4011 Hammam 4002 Sousse, Tunisia \\ ${ }^{2}$ Department of Mathematics, Atilim University, Incek, 06836 Ankara, Turkey
}

Correspondence should be addressed to İnci M. Erhan, ierhan@atilim.edu.tr

Received 25 April 2012; Revised 5 June 2012; Accepted 6 June 2012

Academic Editor: Dumitru Baleanu

Copyright (C) 2012 Hassen Aydi et al. This is an open access article distributed under the Creative Commons Attribution License, which permits unrestricted use, distribution, and reproduction in any medium, provided the original work is properly cited.

We prove coupled coincidence point and coupled fixed point results of $F: X \times X \rightarrow X$ and $g: X \rightarrow$ $X$ involving Meir-Keeler type contractions on the class of partially ordered metric spaces. Our results generalize some recent results in the literature. Also, we give some illustrative examples and application.

\section{Introduction and Preliminaries}

Fixed point theory has wide applications in many areas. In economics it has applications in the study of market stability, in dynamic systems it is used to deterministic timed systems on feedback semantics, and in the theory of differential and integral equations to demonstrate the existence and uniqueness of solutions; see, for example, [1-5]. On the other hand, fixed point theory, in particular fixed point iteration, has also numerous applications in engineering. For example, use of the fixed point iteration in image retrieval provides much better accuracy [6]. Fixed point algorithms proved to be very successful in practical optimization of the contrast functions in independent component analysis in neural-network research, as well as in statistics and signal processing [7]. These algorithms optimize the contrast functions very fast and reliably. Relaxation in linear systems and relaxation and stability in neural networks are also analyzed by means of fixed point iteration [8].

The problem of existence and uniqueness of fixed points in partially ordered sets has been studied thoroughly because of its interesting nature. The first result in this direction was 
given by Turinici [9], where he extended the Banach contraction principle in partially ordered sets. Ran and Reurings [10] presented some applications of Turinici's theorem to matrix equations. The result of Turinici was further extended and refined in [11-25]. In particular, Gnana Bhaskar and Lakshmikantham in [12] introduced the concept of coupled fixed point of a mapping $F: X \times X \rightarrow X$ and investigated some coupled fixed point theorems in partially ordered sets. They also discussed an application of their result by investigating the existence and uniqueness of solution of the periodic boundary value problem:

$$
\begin{gathered}
u^{\prime}(t)=f(t, u(t)), \quad t \in[0, T], \\
u(0)=u(T),
\end{gathered}
$$

where the function $f$ satisfies certain conditions. Following this trend, Harjani et al. [4] studied the existence and uniqueness of solutions of a nonlinear integral equation as an application of coupled fixed points. Very recently, motivated by [5], Jleli and Samet [13] discussed the existence and uniqueness of a positive solution for the singular nonlinear fractional differential equation boundary value problem:

$$
\begin{aligned}
D_{0^{+}}^{\alpha} u(t) & =f(t, u(t), u(t)), \quad 0<t<1, \\
u(0) & =u(1)=u^{\prime}(0)=u^{\prime}(1)=0,
\end{aligned}
$$

where $3<\alpha \leq 4$ is a real number, $D_{0^{+}}^{\alpha}$ is the Riemann-Liouville fractional derivative and $f:(0,1] \times[0, \infty) \times[0, \infty) \rightarrow[0, \infty)$ is continuous, $\lim _{t \rightarrow 0^{+}} f(t, \cdot, \cdot)=+\infty(f$ is singular at $t=0)$ for all $t \in(0,1], f(t, \cdot, \cdot)$ is nondecreasing with respect to first component and decreasing with respect to its second and third components.

On the other hand, Lakshmikantham and Ćirić [19] proved coupled coincidence and common coupled fixed point theorems for nonlinear contractive mappings in partially ordered complete metric spaces which extend the coupled fixed point theorem given in [12]. Recently, Samet [23] proved some coupled fixed point theorems under a generalized MeirKeeler contractive condition.

In this paper, we introduce the definition of weak generalized g-Meir-Keeler type contractions and prove some coupled coincidence point theorems for such contractions. The theorems presented here generalize, enrich, and improve the previous results. Moreover, they have application potential in the theory of existence and uniqueness of solutions of boundary value problems.

Hereafter, we assume that $X \neq \emptyset$ and we use the notation

$$
X^{k}=\underbrace{X \times X \times \cdots \times X}_{k \text {-many }} .
$$

Let $\mathbb{R}$ be the set of real numbers. 
Definition 1.1 (see [12]). Let $(X, \leq)$ be a partially ordered set and $F: X^{2} \rightarrow X$. The mapping $F$ is said to have the mixed monotone property if $F(x, y)$ is monotone nondecreasing in $x$ and monotone nonincreasing in $y$; that is, for any $x, y \in X$,

$$
\begin{array}{ll}
x_{1} \leq x_{2} \Longrightarrow F\left(x_{1}, y\right) \leq F\left(x_{2}, y\right), & \text { for } x_{1}, x_{2} \in X, \\
y_{1} \leq y_{2} \Longrightarrow F\left(x, y_{2}\right) \leq F\left(x, y_{1}\right), & \text { for } y_{1}, y_{2} \in X
\end{array}
$$

Definition 1.2 (see [12]). An element $(x, y) \in X^{2}$ is said to be a coupled fixed point of the mapping $F: X^{2} \rightarrow X$ if

$$
F(x, y)=x, \quad F(y, x)=y \text {. }
$$

The following result of Gnana Bhaskar and Lakshmikantham [12] was also proved in the context of cone metric spaces in [16].

Theorem 1.3 (see [12]). Let $(X, \leq)$ be a partially ordered set, and suppose that there is a metric $d$ on $X$ such that $(X, d)$ is a complete metric space. Let $F: X \times X \rightarrow X$ be a given mapping having the mixed monotone property on $X$. Assume that there exists $k \in[0,1)$ with

$$
d(F(x, y), F(u, v)) \leq \frac{k}{2}[d(x, u)+d(y, v)], \quad \forall u \leq x, y \leq v
$$

Assume either $F$ is continuous, or X satisfies the following property:

(i) if a nondecreasing sequence $\left\{x_{n}\right\} \in X$ converges to $x$, then $x_{n} \leq x$, for all $n$;

(ii) if a nonincreasing sequence $\left\{y_{n}\right\} \in X$ converges to $y_{\text {, then }} y \leq y_{n}$, for all $n$.

If there exist $x_{0}, y_{0} \in X$ such that $x_{0} \leq F\left(x_{0}, y_{0}\right)$ and $F\left(y_{0}, x_{0}\right) \leq y_{0}$, then, there exist $x, y \in X$ such that $x=F(x, y)$ and $y=F(y, x)$.

Inspired by Definition 1.1, Lakshmikantham and Ćirić [19] introduced the concept of the mixed $g$-monotone property.

Definition 1.4 (see [19]). Let $(X, \leq)$ be a partially ordered set. Let $F: X^{2} \rightarrow X$ and let $g: X \rightarrow$ $X$. The mapping $F$ is said to have the mixed $g$-monotone property if $F(x, y)$ is monotone $g$-nondecreasing in $x$ and is monotone $g$-nonincreasing in $y$; that is, for any $x, y \in X$,

$$
\begin{aligned}
& g\left(x_{1}\right) \leq g\left(x_{2}\right) \Longrightarrow F\left(x_{1}, y\right) \leq F\left(x_{2}, y\right), \quad \text { for } x_{1}, x_{2} \in X, \\
& g\left(y_{1}\right) \leq g\left(y_{2}\right) \Longrightarrow F\left(x, y_{2}\right) \leq F\left(x, y_{1}\right), \quad \text { for } y_{1}, y_{2} \in X .
\end{aligned}
$$

It is clear that Definition 1.4 reduces to Definition 1.1 when $g$ is the identity map.

Definition 1.5 (see [19]). An element $(x, y) \in X^{2}$ is called a coupled coincidence point of the mappings $F: X^{2} \rightarrow X$ and $g: X \rightarrow X$ if

$$
F(x, y)=g(x), \quad F(y, x)=g(y) .
$$


Moreover, $(x, y) \in X^{2}$ is called a common coupled fixed point of $F$ and $g$ if

$$
F(x, y)=g(x)=x, \quad F(y, x)=g(y)=y .
$$

Definition 1.6 (see [19]). Let $F: X^{2} \rightarrow X$ and let $g: X \rightarrow X$. The mappings $F$ and $g$ are said to commute if

$$
g(F(x, y))=F(g(x), g(y)), \quad \forall x, y \in X
$$

In 2009, Lakshmikantham and Ćirić [19] also proved a common coupled fixed point on partially ordered complete metric spaces.

Theorem 1.7 (see [19]). Let $(X, \leq)$ be a partially ordered set, and suppose that there is a metric $d$ on $X$ such that $(X, d)$ is a complete metric space. Let $F: X^{2} \rightarrow X$ and let $g: X \rightarrow X$ such that $F$ has the mixed g-monotone property. Suppose that there exists $k \in[0,1)$ such that

$$
d(F(x, y), F(u, v)) \leq \frac{k}{2}[d(g(x), g(u))+d(g(y), g(v))]
$$

for all $x, y, u, v \in X$ for which $g(x) \leq g(u)$ and $g(v) \leq g(y)$. Suppose $F\left(X^{2}\right) \subseteq g(X), g$ is continuous and commutes with $F$. Also suppose that either $F$ is continuous or $X$ has the following property:

$$
\begin{aligned}
& \text { if a nondecreasing sequence }\left\{x_{n}\right\} \longrightarrow x \text {, then } x_{n} \leq x, \forall n \text {, } \\
& \text { if a nonincreasing sequence }\left\{y_{n}\right\} \longrightarrow y \text {, then } y \leq y_{n}, \forall n \text {. }
\end{aligned}
$$

If there exist $x_{0}, y_{0} \in X$ such that $g\left(x_{0}\right) \leq F\left(x_{0}, y_{0}\right)$ and $g\left(y_{0}\right) \geq F\left(y_{0}, x_{0}\right)$, then there exist $x, y \in X$ such that $g(x)=F(x, y)$ and $g(y)=F(y, x)$; that is, $F$ and $g$ have a coupled coincidence point.

In 2010, Samet [23] introduced the mixed strict monotone property.

Definition 1.8 (see [23]). Let $(X, \leq)$ be a partially ordered set and let $F: X^{2} \rightarrow X$. $F$ is said to have mixed strict monotone property if $F(x, y)$ is monotone increasing in $x$ and is monotone decreasing in $y$; that is, for any $x, y \in X$,

$$
\begin{aligned}
& x_{1}<x_{2} \Longrightarrow F\left(x_{1}, y\right)<F\left(x_{2}, y\right), \quad \text { for } x_{1}, x_{2} \in X, \\
& y_{1}<y_{2} \Longrightarrow F\left(x, y_{2}\right)<F\left(x, y_{1}\right), \quad \text { for } y_{1}, y_{2} \in X
\end{aligned}
$$

Also, Samet [23] defined generalized Meir-Keeler contractions as follows.

Definition 1.9 (see [23]). Let $(X, \leq)$ be a partially ordered set, and suppose that there is a metric $d$ on $X$. Let $F: X \times X \rightarrow X$. The mapping $F$ is said to be a generalized Meir-Keeler type contraction if for any $\varepsilon>0$ there exists $\delta(\varepsilon)>0$ such that

$$
\varepsilon \leq \frac{1}{2}[d(x, u)+d(y, v)]<\varepsilon+\delta(\varepsilon) \Longrightarrow d(F(x, y), F(u, v))<\varepsilon,
$$

for all $x, y, u, v \in X$ with $x \leq u, y \geq v$. 
The existence and uniqueness of common coupled coincidence points via generalized Meir-Keeler type contractions was investigated by Samet [23].

Theorem 1.10 (see [23]). Let $(X, \leq)$ be a partially ordered set, and suppose that there is a metric $d$ on $X$ such that $(X, d)$ is a complete metric space. Let $F: X^{2} \rightarrow X$ be a map satisfying the following conditions:

(i) F has the mixed strict monotone property,

(ii) $F$ is a generalized Meir-Keeler type contraction,

(iii) there exist $x_{0}, y_{0} \in X$ such that

$$
x_{0}<F\left(x_{0}, y_{0}\right), \quad y_{0} \geq F\left(y_{0}, x_{0}\right) .
$$

Assume either $F$ is continuous or $X$ satisfies the following property:

(i) if a nondecreasing sequence $\left\{x_{n}\right\} \in X$ converges to $x$, then $x_{n} \leq x$, for all $n$,

(ii) if a nonincreasing sequence $\left\{y_{n}\right\} \in X$ converges to $y_{\text {, then }} y \leq y_{n}$, for all $n$.

Then $F$ has a coupled fixed point in $X^{2}$; that is, there exist $x, y \in X$ such that

$$
F(x, y)=x, \quad F(y, x)=y
$$

Very recently, Gordji et al. [26] replaced the mixed g-monotone property by the mixed strict g-monotone property.

Definition 1.11 (see [26]). Let $(X, \leq)$ be a partially ordered set. Let $F: X^{2} \rightarrow X$ and let $g: X \rightarrow$ $X$. $F$ is said to have the mixed strict $g$-monotone property if $F(x, y)$ is monotone $g$-increasing in $x$ and is monotone $g$-decreasing in $y$; that is, for any $x, y \in X$,

$$
\begin{array}{cc}
g\left(x_{1}\right)<g\left(x_{2}\right) \Longrightarrow F\left(x_{1}, y\right)<F\left(x_{2}, y\right), & \text { for } x_{1}, x_{2} \in X, \\
g\left(y_{1}\right)<g\left(y_{2}\right) \Longrightarrow F\left(x, y_{2}\right)<F\left(x, y_{1}\right), & \text { for } y_{1}, y_{2} \in X
\end{array}
$$

If we replace $g$ with identity map in (1.17), we get Definition 1.8 of the mixed strict monotone property of $F$.

Gordji et al. [26] gave also the following definition.

Definition 1.12 (see [26]). Let $(X, d, \leq)$ be a partially ordered metric space and $F: X \times X \rightarrow X$, $g: X \rightarrow X$. The operator $F$ is said to be a generalized $g$-Meir-Keeler type contraction if for any $\varepsilon>0$ there exists $\delta(\varepsilon)>0$ such that

$$
\varepsilon \leq \frac{1}{2}[d(g(x), g(u))+d(g(y), g(v))]<\varepsilon+\delta(\varepsilon) \Longrightarrow d(F(x, y), F(u, v))<\varepsilon
$$

for all $x, y, u, v \in X$ with $g(x) \leq g(u), g(y) \geq g(v)$.

Note that if we replace $g$ with the identity in (1.18), we get Definition 1.9 of generalized Meir-Keeler type contraction. 
Gordji et al. [26] proved the following theorem.

Theorem 1.13 (see [26]). Let $(X, \leq)$ be a partially ordered set, and suppose that there is a metric $d$ on $X$ such that $(X, d)$ is a complete metric space. Let $F: X^{2} \rightarrow X$ and let $g: X \rightarrow X$ be mappings such that $F\left(X^{2}\right) \subseteq g(X), g$ is continuous and commutes with $F$. Suppose also that $F$ satisfies the following conditions:

(i) $F$ is continuous,

(ii) F has the mixed strict g-monotone property,

(iii) $F$ is a generalized $g$-Meir-Keeler type contraction,

(iv) there exist $x_{0}, y_{0} \in X$ such that

$$
g\left(x_{0}\right)<F\left(x_{0}, y_{0}\right), \quad g\left(y_{0}\right) \geq F\left(y_{0}, x_{0}\right)
$$

Then $F$ and $g$ have a coupled coincidence point in $X^{2}$; that is, there exist $x, y \in X$ such that

$$
F(x, y)=g(x), \quad F(y, x)=g(y) .
$$

In this paper, we proved coupled coincidence point results in the setting of partially ordered metric spaces. Also, the existence and uniqueness of a common coupled fixed point of $F: X \times X \rightarrow X$ and $g: X \rightarrow X$ is studied. Our results improve the results of Berinde [15] and Gordji et al. [26]. We give two examples and an application that illustrate our results.

\section{Existence of Coupled Fixed Point}

We start this section with the following definition which is modification of Definition 1.12.

Definition 2.1. Let $(X, \leq)$ be a partially ordered set, and suppose that there is a metric $d$ on $X$ such that $(X, d)$ is a metric space. Let $F: X \times X \rightarrow X$ and $g: X \rightarrow X$. The mapping $F$ is said to be a weak generalized $g$-Meir-Keeler type contraction if for any $\varepsilon>0$ there exists $\delta(\varepsilon)>0$ such that

$$
\begin{aligned}
\varepsilon & \leq \frac{1}{2}[d(g(x), g(u))+d(g(y), g(v))]<\varepsilon+\delta(\varepsilon) \\
& \Longrightarrow \frac{1}{2}[d(F(x, y), F(u, v))+d(F(y, x), F(v, u))]<\varepsilon
\end{aligned}
$$

for all $x, y, u, v \in X$ with $g(x) \leq g(u)$ and $g(y) \geq g(v)$.

Remark 2.2. If we replace $g$ with the identity in (2.1), we get the definition of a weak MeirKeeler type contraction; that is, for all $\varepsilon>0$ there exists $\delta(\varepsilon)>0$ such that

$$
\varepsilon \leq \frac{1}{2}[d(x, u)+d(y, v)]<\varepsilon+\delta(\varepsilon) \Longrightarrow \frac{1}{2}[d(F(x, y), F(u, v))+d(F(y, x), F(v, u))]<\varepsilon,
$$

for all $x, y, u, v \in X$ with $x \leq u$ and $y \geq v$. 
Note that (2.2) corresponds to a Meir-Keeler contraction type studied very recently by Berinde [15].

The following fact can be derived easily from Definition 2.1.

Lemma 2.3. Let $(X, \leq)$ be a partially ordered set, and suppose that there is a metric $d$ on $X$ such that $(X, d)$ is a metric space. Let $F: X \times X \rightarrow X$ and $g: X \rightarrow X$. If $F$ is a weak generalized g-Meir-Keeler type contraction, then we have

$$
d(F(x, y), F(u, v))+d(F(y, x), F(v, u))<[d(g(x), g(u))+d(g(y), g(v))],
$$

for all $x, y, u, v \in X$ with $g(x)<g(u), g(y) \geq g(v)$ or $g(x) \leq(u), g(y)>g(v)$.

Proof. Without loss of generality, suppose that $g(x)<g(u), g(y) \geq g(v)$ where $x, y, u, v \in X$. It is clear that $d(g(x), g(u))+d(g(y), g(v))>0$. Set $\varepsilon=(1 / 2)[d(g(x), g(u))+d(g(y), g(v))]>$ 0 . Since $F$ is a weak generalized $g$-Meir-Keeler type contraction, then for this $\varepsilon$, there exits $\delta=\delta(\varepsilon)>0$ such that

$$
\begin{aligned}
\varepsilon & \leq \frac{1}{2}\left[d\left(g\left(x_{0}\right), g\left(u_{0}\right)\right)+d\left(g\left(y_{0}\right), g\left(v_{0}\right)\right)\right]<\varepsilon+\delta \\
& \Longrightarrow \frac{1}{2}\left[d\left(F\left(x_{0}, y_{0}\right), F\left(u_{0}, v_{0}\right)\right)+d\left(F\left(y_{0}, x_{0}\right), F\left(v_{0}, u_{0}\right)\right)\right]<\varepsilon,
\end{aligned}
$$

for all $x_{0}, y_{0}, u_{0}, v_{0} \in X$ with $g\left(x_{0}\right)<g\left(u_{0}\right), g\left(y_{0}\right) \geq g\left(v_{0}\right)$. The result follows by choosing $x=x_{0}, y=y_{0}, u=u_{0}$ and $z=z_{0}$, that is:

$$
d(F(x, y), F(u, v))+d(F(y, x), F(v, u))<d(g(x), g(u))+d(g(y), g(v)) .
$$

Next, we state an existence theorem of a coupled coincidence point for $F: X^{2} \rightarrow X$ and $g: X \rightarrow X$.

Theorem 2.4. Let $(X, \leq)$ be a partially ordered set, and suppose that there is a metric $d$ on $X$ such that $(X, d)$ is a complete metric space. Let $F: X^{2} \rightarrow X$ and $g: X \rightarrow X$ be mappings such that $F\left(X^{2}\right) \subseteq g(X)$. Moreover, assume that $g$ is continuous and commutes with $F$. Suppose also that the following conditions hold:

(i) $F$ is continuous,

(ii) F has the mixed strict g-monotone property,

(iii) $F$ is a weak generalized $g$-Meir-Keeler type contraction,

(iv) there exist $x_{0}, y_{0} \in X$ such that

$$
g\left(x_{0}\right)<F\left(x_{0}, y_{0}\right), \quad g\left(y_{0}\right) \geq F\left(y_{0}, x_{0}\right) .
$$

Then $F$ and $g$ have a coupled coincidence point; that is, there exist $x, y \in X$ such that

$$
F(x, y)=g(x), \quad F(y, x)=g(y) .
$$


Proof. Let $\left(x_{0}, y_{0}\right) \in X^{2}$ be a point satisfying (iv); that is, $g\left(x_{0}\right)<F\left(x_{0}, y_{0}\right)$ and $g\left(y_{0}\right) \geq$ $F\left(y_{0}, x_{0}\right)$. We define the sequences $\left\{x_{n}\right\}$ and $\left\{y_{n}\right\}$ in the following way. Because of the assumption $F\left(X^{2}\right) \subseteq g(X)$, we can choose $\left(x_{1}, y_{1}\right) \in X^{2}$ such that $g\left(x_{1}\right)=F\left(x_{0}, y_{0}\right)$ and $g\left(y_{1}\right)=F\left(y_{0}, x_{0}\right)$. By the same argument, we can take $\left(x_{2}, y_{2}\right) \in X^{2}$ in such a way that $g\left(x_{2}\right)=F\left(x_{1}, y_{1}\right)$ and $g\left(y_{2}\right)=F\left(y_{1}, x_{1}\right)$. Inductively, we define

$$
g\left(x_{n+1}\right)=F\left(x_{n}, y_{n}\right), \quad g\left(y_{n+1}\right)=F\left(y_{n}, x_{n}\right) \quad \forall n=0,1,2, \ldots
$$

We claim that the the sequence $\left\{g\left(x_{n}\right)\right\}$ is increasing and the sequence $\left\{g\left(y_{n}\right)\right\}$ is decreasing, that is:

$$
\begin{aligned}
& \cdots>g\left(x_{n}\right)>g\left(x_{n-1}\right)>\cdots>g\left(x_{1}\right)>g\left(x_{0}\right), \\
& \cdots<g\left(y_{n}\right)<g\left(y_{n-1}\right)<\cdots<g\left(y_{1}\right) \leq g\left(y_{0}\right) .
\end{aligned}
$$

We will use mathematical induction to show (2.9). By assumption (iv), we have

$$
g\left(x_{0}\right)<F\left(x_{0}, y_{0}\right)=g\left(x_{1}\right), \quad g\left(y_{0}\right) \geq F\left(y_{0}, x_{0}\right)=g\left(y_{1}\right) .
$$

Assume that (2.9) holds for some $n \geq 1$. Regarding the mixed strict $g$-monotone property of $F$, we have

$$
g\left(x_{n-1}\right)<g\left(x_{n}\right) \Longrightarrow\left\{\begin{array}{l}
F\left(x_{n-1}, y_{n-1}\right)<F\left(x_{n}, y_{n-1}\right) \\
F\left(y_{n-1}, x_{n-1}\right)>F\left(y_{n-1}, x_{n}\right)
\end{array}\right.
$$

By repeating the same arguments, we observe that

$$
g\left(y_{n-1}\right)>g\left(y_{n}\right) \Longrightarrow\left\{\begin{array}{l}
F\left(x_{n}, y_{n-1}\right)<F\left(x_{n}, y_{n}\right), \\
F\left(y_{n-1}, x_{n}\right)>F\left(y_{n}, x_{n}\right) .
\end{array}\right.
$$

Combining the previous inequalities, together with (2.8), we get

$$
\begin{aligned}
& g\left(x_{n}\right)=F\left(x_{n-1}, y_{n-1}\right)<F\left(x_{n}, y_{n}\right)=g\left(x_{n+1}\right), \\
& g\left(y_{n}\right)=F\left(y_{n-1}, x_{n-1}\right)>F\left(y_{n}, x_{n}\right)=g\left(y_{n+1}\right) .
\end{aligned}
$$

We conclude that (2.9) holds for all $n \geq 1$. Set

$$
\Delta_{n}=d\left(g\left(x_{n}\right), g\left(x_{n+1}\right)\right)+d\left(g\left(y_{n}\right), g\left(y_{n+1}\right)\right) \text {. }
$$


Making use of Lemma 2.3 and (2.8), we obtain

$$
\begin{aligned}
& d\left(g\left(x_{n}\right), g\left(x_{n+1}\right)\right)+d\left(g\left(y_{n}\right), g\left(y_{n+1}\right)\right) \\
& \quad=d\left(F\left(x_{n-1}, y_{n-1}\right), F\left(x_{n}, y_{n}\right)\right)+d\left(F\left(y_{n-1}, x_{n-1}\right), F\left(y_{n}, x_{n}\right)\right) \\
& \quad<d\left(g\left(x_{n-1}\right), g\left(x_{n}\right)\right)+d\left(g\left(y_{n-1}\right), g\left(y_{n}\right)\right) .
\end{aligned}
$$

Thus, we have $\Delta_{n}<\Delta_{n-1}$. Hence, the sequence $\left\{\Delta_{n}\right\}$ is monotone decreasing and clearly bounded below by 0 . Therefore, $\lim _{n \rightarrow \infty} \Delta_{n}=L$ for some $L \geq 0$.

We show that $L=0$. Suppose the contrary; that is, $L \neq 0$. Then, for some positive integer $k$, we have for all $n \geq k$

$$
\varepsilon \leq \frac{\Delta_{n}}{2}=\frac{1}{2}\left[d\left(g\left(x_{n}\right), g\left(x_{n+1}\right)\right)+d\left(g\left(y_{n}\right), g\left(y_{n+1}\right)\right)\right]<\varepsilon+\delta(\varepsilon),
$$

where we choose $\varepsilon=L / 2$. In particular, for $n=k$

$$
\varepsilon \leq \frac{\Delta_{k}}{2}=\frac{1}{2}\left[d\left(g\left(x_{k}\right), g\left(x_{k+1}\right)\right)+d\left(g\left(y_{k}\right), g\left(y_{k+1}\right)\right)\right]<\varepsilon+\delta(\varepsilon) .
$$

Regarding the assumption (iii) and (2.17), we have

$$
\frac{1}{2}\left[d\left(F\left(x_{k}, y_{k}\right), F\left(x_{k+1}, y_{k+1}\right)\right)+d\left(F\left(y_{k}, x_{k}\right), F\left(y_{k+1}, x_{k+1}\right)\right)\right]<\varepsilon
$$

which by (2.8) is equivalent to

$$
\frac{1}{2}\left[d\left(g\left(x_{k+1}\right), g\left(x_{k+2}\right)\right)+d\left(g\left(y_{k+1}\right), g\left(y_{k+2}\right)\right)\right]<\varepsilon .
$$

Hence, we obtain

$$
\frac{\Delta_{k+1}}{2}<\varepsilon,
$$

which contradicts (2.16) for $n=k+1$. Thus, we deduce that $L=0$, that is:

$$
\lim _{n \rightarrow \infty} \Delta_{n}=\lim _{n \rightarrow \infty}\left[d\left(g\left(x_{n}\right), g\left(x_{n+1}\right)\right)+d\left(g\left(y_{n}\right), g\left(y_{n+1}\right)\right)\right]=0
$$

This implies that

$$
\lim _{n \rightarrow \infty} d\left(g\left(x_{n}\right), g\left(x_{n+1}\right)\right)=0=\lim _{n \rightarrow \infty} d\left(g\left(y_{n}\right), g\left(y_{n+1}\right)\right) .
$$


We claim that the sequences $\left\{g\left(x_{n}\right)\right\}$ and $\left\{g\left(y_{n}\right)\right\}$ are Cauchy sequences. Take an arbitrary $\varepsilon>0$. It follows from (2.21) that there exists $k \in \mathbb{N}$ such that

$$
\frac{1}{2}\left[d\left(g\left(x_{k}\right), g\left(x_{k+1}\right)\right)+d\left(g\left(y_{k}\right), g\left(y_{k+1}\right)\right)\right]<\delta(\varepsilon) .
$$

Without loss of the generality, assume that $\delta(\varepsilon) \leq \varepsilon$ and define the following set:

$$
\Pi:=\left\{(x, y) \in X^{2}: d\left(x, g\left(x_{k}\right)\right)+d\left(y, g\left(y_{k}\right)\right)<2(\varepsilon+\delta(\varepsilon)), x>g\left(x_{k}\right), y \leq g\left(y_{k}\right)\right\} .
$$

Take $\wedge=(g(X), g(X)) \cap \Pi$. We claim that

$$
(F(p, q), F(q, p)) \in \wedge \quad \forall(x, y)=(g(p), g(q)) \in \wedge \text { where } p, q \in X .
$$

Take $(x, y)=(g(p), g(q)) \in \Pi$. Then, by (2.23) and the triangle inequality we have

$$
\begin{aligned}
\frac{1}{2}\left[d\left(g\left(x_{k}\right), F(p, q)\right)+d\left(g\left(y_{k}\right), F(q, p)\right)\right] \\
\leq \frac{1}{2}\left[d\left(g\left(x_{k}\right), g\left(x_{k+1}\right)\right)+d\left(g\left(x_{k+1}\right), F(p, q)\right)\right] \\
\quad+\frac{1}{2}\left[d\left(g\left(y_{k}\right), g\left(y_{k+1}\right)\right)+d\left(g\left(y_{k+1}\right), F(q, p)\right)\right] \\
=\frac{1}{2}\left[d\left(g\left(x_{k}\right), g\left(x_{k+1}\right)\right)+d\left(g\left(y_{k}\right), g\left(y_{k+1}\right)\right)\right]+\frac{1}{2} d\left(F(p, q), F\left(x_{k}, y_{k}\right)\right) \\
\quad+\frac{1}{2} d\left(F\left(y_{k}, x_{k}\right), F(q, p)\right) \\
<\delta(\varepsilon)+\frac{1}{2} d\left(F(p, q), F\left(x_{k}, y_{k}\right)\right)+\frac{1}{2} d\left(F\left(y_{k}, x_{k}\right), F(q, p)\right) .
\end{aligned}
$$

We distinguish two cases.

First Case. $(1 / 2)\left[d\left(x, g\left(x_{k}\right)\right)+d\left(y, g\left(y_{k}\right)\right)\right]=(1 / 2)\left[d\left(g(p), g\left(x_{k}\right)\right)+d\left(g(q), g\left(y_{k}\right)\right)\right] \leq \varepsilon$.

By Lemma 2.3 and the definition of $\Pi$, (2.26) turns into

$$
\begin{aligned}
& \frac{1}{2}\left[d\left(g\left(x_{k}\right), F(p, q)\right)+d\left(g\left(y_{k}\right), F(q, p)\right)\right] \\
& \quad<\delta(\varepsilon)+\frac{1}{2} d\left(F(p, q), F\left(x_{k}, y_{k}\right)\right)+\frac{1}{2} d\left(F\left(y_{k}, x_{k}\right), F(q, p)\right) \\
& \quad<\delta(\varepsilon)+\frac{1}{2}\left[d\left(g(p), g\left(x_{k}\right)\right)+d\left(g(q), g\left(y_{k}\right)\right)\right] \leq \delta(\varepsilon)+\varepsilon
\end{aligned}
$$

Second Case. $\varepsilon<(1 / 2)\left[d\left(x, g\left(x_{k}\right)\right)+d\left(y, g\left(y_{k}\right)\right)\right]=(1 / 2)\left[d\left(g(p), g\left(x_{k}\right)\right)+d\left(g(q), g\left(y_{k}\right)\right)\right]<$ $\varepsilon+\delta(\varepsilon)$. 
In this case, we have

$$
\varepsilon<\frac{1}{2}\left[d\left(g(p), g\left(x_{k}\right)\right)+d\left(g(q), g\left(y_{k}\right)\right)\right]<\varepsilon+\delta(\varepsilon) .
$$

Since $x=g(p)>g\left(x_{k}\right)$ and $y=g(q) \leq g\left(y_{k}\right)$, by (ii), we get

$$
\frac{1}{2}\left[d\left(F(p, q), F\left(x_{k}, y_{k}\right)\right)+d\left(F\left(y_{k}, x_{k}\right), F(q, p)\right)\right]<\varepsilon .
$$

Thus, combining (2.26) and (2.29), we obtain

$$
\frac{1}{2}\left[d\left(g\left(x_{k}\right), F(p, q)\right)+d\left(g\left(y_{k}\right), F(q, p)\right)\right]<\varepsilon+\delta(\varepsilon) .
$$

On the other hand, using (i), it is obvious that

$$
F(p, q)>g\left(x_{k}\right), \quad F(q, p) \leq g\left(y_{k}\right) .
$$

We conclude that $(F(p, q), F(q, p)) \in \Pi$. Since $F\left(X^{2}\right) \subset g(X)$, so

$$
(F(p, q), F(q, p)) \in \wedge
$$

that is, (2.25) holds. By (2.23), we have $\left(g\left(x_{k+1}\right), g\left(y_{k+1}\right)\right) \in \wedge$. This implies with (2.25) that

$$
\begin{aligned}
\left(g\left(x_{k+1}\right), g\left(y_{k+1}\right)\right) \in \wedge & \Longrightarrow\left(F\left(x_{k+1}, y_{k+1}\right), F\left(y_{k+1}, x_{k+1}\right)\right)=\left(g\left(x_{k+2}\right), g\left(y_{k+2}\right)\right) \in \wedge \\
& \Longrightarrow\left(F\left(x_{k+2}, y_{k+2}\right), F\left(y_{k+2}, x_{k+2}\right)\right)=\left(g\left(x_{k+3}\right), g\left(y_{k+3}\right)\right) \in \wedge \\
& \Longrightarrow \cdots \Longrightarrow\left(g\left(x_{n}\right), g\left(y_{n}\right)\right) \in \wedge \Longrightarrow \cdots
\end{aligned}
$$

Then, for all $n>k$, we have $\left(g\left(x_{n}\right), g\left(y_{n}\right)\right) \in \wedge$. This implies that for all $n, m>k$, we have

$$
\begin{aligned}
d\left(g\left(x_{n}\right), d\left(x_{m}\right)\right)+d\left(g\left(y_{n}\right), g\left(y_{m}\right)\right) \leq & d\left(g\left(x_{n}\right), g\left(x_{k}\right)\right)+d\left(g\left(y_{n}\right), g\left(y_{k}\right)\right) \\
& +d\left(g\left(x_{k}\right), g\left(x_{m}\right)\right)+d\left(g\left(y_{k}\right), g\left(y_{m}\right)\right) \\
& <4(\varepsilon+\delta(\varepsilon)) \leq 8 \varepsilon .
\end{aligned}
$$

Thus, the sequences $\left\{g\left(x_{n}\right)\right\}$ and $\left\{g\left(y_{n}\right)\right\}$ are Cauchy in $(X, d)$.

Since $(X, d)$ is complete, so there exist $x, y \in X$ such that

$$
\begin{aligned}
& \lim _{n \rightarrow \infty} d\left(x, g\left(x_{n}\right)\right)=0, \\
& \lim _{n \rightarrow \infty} d\left(y, g\left(y_{n}\right)\right)=0 .
\end{aligned}
$$


Finally, by continuity of $F$ and $g$, the commutativity of $F$ and $g$, and using exactly the same argument of Lakshmikantham and Ćirić [19], we get that $F(x, y)=g(x)$ and $F(y, x)=g(y)$, which completes the proof.

Remark 2.5. Theorem 2.4 holds if we replace (iv) by the following: there exist $x_{0}, y_{0} \in X$ such that

$$
g\left(x_{0}\right) \leq F\left(x_{0}, y_{0}\right), \quad g\left(y_{0}\right)>F\left(y_{0}, x_{0}\right) .
$$

Theorem 2.6. Let $(X, \leq)$ be a partially ordered set, and suppose that there is a metric $d$ on $X$ such that $(X, d)$ is a metric space. Let $F: X^{2} \rightarrow X$ and let $g: X \rightarrow X$ be mappings such that $F\left(X^{2}\right) \subseteq g(X)$. Assume that $\mathrm{X}$ satisfies the following property:

(a) if $\left\{x_{n}\right\}$ is a sequence such that $x_{n+1}>x_{n}$ for each $n=1,2, \ldots$ and $x_{n} \rightarrow x$, then $x_{n}<x$ for each $n=1,2, \ldots$,

(b) if $\left\{y_{n}\right\}$ is a sequence such that $y_{n+1}<y_{n}$ for each $n=1,2, \ldots$ and $y_{n} \rightarrow y$, then $y_{n}>y$ for each $n=1,2, \ldots$.

Suppose the following conditions hold:

(i) F has the mixed strict g-monotone property,

(ii) $F$ is a weak generalized g-Meir-Keeler type contraction,

(iii) $g(X)$ is a complete subspace of $(X, d)$,

(iv) there exist $x_{0}, y_{0} \in X$ such that

$$
g\left(x_{0}\right)<F\left(x_{0}, y_{0}\right), \quad g\left(y_{0}\right) \geq F\left(y_{0}, x_{0}\right) .
$$

Then $F$ and $g$ have a coupled coincidence point; that is, there exist $x, y \in X$ such that

$$
F(x, y)=g(x), \quad F(y, x)=g(y)
$$

Proof. Proceeding exactly as in Theorem 2.4, we have that $\left\{g\left(x_{n}\right)\right\}$ and $\left\{g\left(y_{n}\right)\right\}$ are Cauchy sequences in the complete metric space $(g(X), d)$. Then, there exist $x, y \in X$ such that $g\left(x_{n}\right) \rightarrow g(x)$ and $g\left(y_{n}\right) \rightarrow g(y)$. Since $\left\{g\left(x_{n}\right)\right\}$ is increasing and $\left\{g\left(y_{n}\right)\right\}$ is decreasing, using the assumptions (a) and (b), we have

$$
g\left(x_{n}\right)<g(x), \quad g\left(y_{n}\right)>g(y),
$$

for each $n \geq 0$. Using triangle inequality together with (2.8), we find

$$
\begin{aligned}
d(F(x, y), g(x)) & \leq d\left(F(x, y), g\left(x_{n}\right)\right)+d\left(g\left(x_{n}\right), g(x)\right) \\
& =d\left(F(x, y), F\left(x_{n-1}, y_{n-1}\right)\right)+d\left(g\left(x_{n}\right), g(x)\right) .
\end{aligned}
$$


Similarly,

$$
\begin{aligned}
d(F(y, x), g(y)) & \leq d\left(F(y, x), g\left(y_{n}\right)\right)+d\left(g\left(y_{n}\right), g(y)\right) \\
& =d\left(F(y, x), F\left(y_{n-1}, x_{n-1}\right)\right)+d\left(g\left(y_{n}\right), g(y)\right) .
\end{aligned}
$$

Taking side-by-side sum of the above mentioned inequalities and having in mind (2.39), the fact that $g\left(x_{n}\right) \rightarrow g(x), g\left(y_{n}\right) \rightarrow g(y)$ and Lemma 2.3, we get

$$
\begin{aligned}
& d(F(x, y), g(x))+d(F(y, x), g(y)) \\
& \leq d\left(F(x, y), F\left(x_{n-1}, y_{n-1}\right)\right)+d\left(F(y, x), F\left(y_{n-1}, x_{n-1}\right)\right) \\
& \quad+d\left(g\left(x_{n}\right), g(x)\right)+d\left(g\left(y_{n}\right), g(y)\right) \\
&<\left[d\left(g(x), g\left(x_{n-1}\right)\right)+d\left(g(y), g\left(y_{n-1}\right)\right)\right]+d\left(g\left(x_{n}\right), g(x)\right)+d\left(g\left(y_{n}\right), g(y)\right) \longrightarrow 0,
\end{aligned}
$$

as $n \rightarrow \infty$. Hence, we end up with $d(F(x, y), g(x))=0=d(F(y, x), g(y))$, that is, $F(x, y)=$ $g(x)$ and $F(y, x)=g(y)$, which completes the proof.

As a particular case of Theorems 2.4 and 2.6, we state the following corollary where the function $g$ is taken as the identity function.

Corollary 2.7. Let $(X, \leq)$ be a partially ordered set, and suppose that there is a metric $d$ on $X$ such that $(X, d)$ is a complete metric space. Let $F: X^{2} \rightarrow X$. Suppose that $F$ satisfies the following conditions:

(i) F has the mixed strict monotone property,

(ii) $F$ is a weak Meir-Keeler type contraction,

(iii) there exist $x_{0}, y_{0} \in X$ such that

$$
x_{0}<F\left(x_{0}, y_{0}\right), \quad y_{0} \geq F\left(y_{0}, x_{0}\right)
$$

Assume either $F$ is continuous or X satisfies the following property:

(a) if $\left\{x_{n}\right\}$ is a sequence such that $x_{n+1}>x_{n}$ for each $n=1,2, \ldots$ and $x_{n} \rightarrow x$, then $x_{n}<x$ for each $n=1,2, \ldots$,

(b) if $\left\{y_{n}\right\}$ is a sequence such that $y_{n+1}<y_{n}$ for each $n=1,2, \ldots$ and $y_{n} \rightarrow y$, then $y_{n}>y$ for each $n=1,2, \ldots$.

Then $F$ has a coupled fixed point; that is, there exist $x, y \in X$ such that

$$
F(x, y)=x, \quad F(y, x)=y
$$

We give the following examples. 
Example 2.8. Let $X=\mathbb{R}$ and $d(x, y)=|x-y|$. Set $F: X^{2} \rightarrow X$ and let $g: X \rightarrow X$ be defined as $F(x, y)=\left(3 x^{3}-7 y^{3}\right) / 12$ and $g(x)=x^{3}$. Then, the mapping $F$ has the strict mixed monotone property. We claim that condition (2.1) holds, but the condition (1.18) is not satisfied.

Note that in order to guarantee (1.18), we must have

$$
\varepsilon \leq \frac{1}{2}[d(g(x), g(u))+d(g(y), g(v))]<\varepsilon+\delta(\varepsilon) \Longrightarrow d(F(x, y), F(u, v))<\varepsilon,
$$

for $x, y, u, v \in X$ with $g(x) \leq g(u), g(y) \geq g(v)$. This means that

$$
\varepsilon \leq \frac{1}{2}\left(\left|x^{3}-u^{3}\right|+\left|y^{3}-v^{3}\right|\right)<\varepsilon+\delta(\varepsilon) \Longrightarrow\left|\frac{3 x^{3}-7 y^{3}}{12}-\frac{3 u^{3}-7 v^{3}}{12}\right|<\varepsilon
$$

Choosing $x=u$ for simplicity (so $g(x)=g(u)$ ), we get

$$
\varepsilon \leq \frac{1}{2}\left(\left|y^{3}-v^{3}\right|\right)<\varepsilon+\delta(\varepsilon), \quad g(y) \geq g(v)
$$

Hence for $g(y)>g(v),(2.46)$ implies that

$$
\left|\frac{3 x^{3}-7 y^{3}}{12}-\frac{3 u^{3}-7 v^{3}}{12}\right|=\left|\frac{7 v^{3}-7 y^{3}}{12}\right|=\frac{7}{12}\left|y^{3}-v^{3}\right|<\varepsilon
$$

Combining (2.47) and(2.48), we get that

$$
2 \varepsilon \leq\left|y^{3}-v^{3}\right|<\frac{12}{7} \varepsilon<2 \varepsilon
$$

which is a contradiction.

On the other hand, $F$ and $g$ satisfy (2.1). Indeed, if we take the sum of

$$
\begin{aligned}
& \left|\frac{3 x^{3}-7 y^{3}}{12}-\frac{3 u^{3}-7 v^{3}}{12}\right| \leq \frac{3}{12}\left|x^{3}-u^{3}\right|+\frac{7}{12}\left|v^{3}-y^{3}\right|, \quad g(x) \leq g(u), g(y) \geq g(v), \\
& \left|\frac{3 y^{3}-7 x^{3}}{12}-\frac{3 v^{3}-7 y^{3}}{12}\right| \leq \frac{3}{12}\left|v^{3}-y^{3}\right|+\frac{7}{12}\left|x^{3}-u^{3}\right|, \quad g(x) \leq g(u), g(y) \geq g(v),
\end{aligned}
$$


and divide by 2 , we obtain for $g(x) \leq g(u)$ and let $g(y) \geq g(v)$

$$
\begin{aligned}
\frac{1}{2}[d(F(x, y), F(u, v))+d(F(y, x), F(v, u))] \\
\quad=\frac{1}{2}\left(\left|\frac{3 x^{3}-7 y^{3}}{12}-\frac{3 u^{3}-7 v^{3}}{12}\right|+\left|\frac{7 x^{3}-3 y^{3}}{12}-\frac{7 u^{3}-3 v^{3}}{12}\right|\right) \\
\quad \leq \frac{5}{12}\left(\left|x^{3}-u^{3}\right|+\left|y^{3}-v^{3}\right|\right) \\
\quad=\frac{5}{6}\left\{\frac{1}{2}[d(g(x), g(u))+d(g(y), g(v))]\right\} .
\end{aligned}
$$

Choosing $\delta(\varepsilon)<\varepsilon / 5$, we get the desired result. Note also that $x_{0}=-1$ and $y_{0}=1$ satisfy (2.6).

So Theorem 2.4 can be applied to $F$ ad $g$ in this example to conclude that $F$ and $g$ have a coupled coincidence point $(0,0)$, while Theorem 1.13 cannot be applied since (1.18) is not satisfied.

Example 2.9. Let $X=\mathbb{R}$ and $d(x, y)=|x-y|$. Set $F: X^{2} \rightarrow X$ and let $g: X \rightarrow X$ be defined as $F(x, y)=(x-2 y) / 4$ and $g(x)=2 x$. Then, the mapping $F$ has the strict mixed monotone property. We claim that condition (2.1) holds for $g(x) \leq g(u)$ and $g(y) \geq g(v)$. Indeed,

$$
\begin{aligned}
\frac{1}{2}[d(F(x, y), F(u, v))+d(F(y, x), F(v, u))] \\
=\frac{1}{2}\left(\left|\frac{x-2 y}{4}-\frac{u-2 v}{4}\right|+\left|\frac{y-2 x}{4}-\frac{v-2 u}{4}\right|\right) \\
=\frac{3}{8}((u-x)+(y-v)) \\
=\frac{3}{8}\left\{\frac{1}{2}[d(g(x), g(u))+d(g(y), g(v))]\right\} .
\end{aligned}
$$

Choosing $\delta(\varepsilon)<5 \varepsilon / 3$, we get the desired result. Note also that $x_{0}=0$ and $y_{0}=1$ satisfy (2.6).

All hypotheses of Theorem 2.4 are satisfied. Here, $F$ and $g$ have a coupled coincidence point $(0,0)$.

\section{Uniqueness of Common Coupled Fixed Point}

In this section we will prove the uniqueness of a common coupled fixed point. We endow the product space $X^{2}$ with the following partial order:

$$
(u, v) \leq(x, y) \Longleftrightarrow u \leq x, y \geq v, \quad \forall(x, y),(u, v) \in X^{2}
$$

Note that a pair $(x, y) \in X^{2}$ is comparable with $(u, v) \in X^{2}$ if either $(x, y) \leq(u, v)$ or $(u, v) \leq$ $(x, y)$. We next state the conditions for the existence and uniqueness of a common coupled fixed point of maps $F$ and $g$. 
Theorem 3.1. In addition to the hypotheses of Theorem 2.4 (resp., Theorem 2.6), assume that for all $(x, y),\left(x^{*}, y^{*}\right) \in X^{2}$, there exists $(a, b) \in X^{2}$ such that $(F(a, b), F(b, a))$ is comparable to both $(F(x, y), F(y, x))$ and $\left(F\left(x^{*}, y^{*}\right), F\left(y^{*}, x^{*}\right)\right)$. Then, $F$ and $g$ have a unique common coupled fixed point, that is:

$$
x=g(x)=F(x, y), \quad y=g(y)=F(y, x) .
$$

Proof. The set of coupled coincidence points of $F$ and $g$ is not empty due to Theorem 2.4 (resp., Theorem 2.6). We suppose that $(x, y),\left(x^{*}, y^{*}\right) \in X^{2}$ are two coupled coincidence points of $F$ and $g$. We distinguish the following two cases.

First Case. $(F(x, y), F(y, x))$ is comparable to $\left(F\left(x^{*}, y^{*}\right), F\left(y^{*}, x^{*}\right)\right.$ with respect to the ordering in $X^{2}$, where

$$
F(x, y)=g(x), \quad F(y, x)=g(y), \quad F\left(x^{*}, y^{*}\right)=g\left(x^{*}\right), \quad F\left(y^{*}, x^{*}\right)=g\left(y^{*}\right) .
$$

Without loss of the generality, we may assume that

$$
g(x)=F(x, y)<F\left(x^{*}, y^{*}\right)=g\left(x^{*}\right), \quad g(y)=F(y, x) \geq F\left(y^{*}, x^{*}\right)=g\left(y^{*}\right) .
$$

By Lemma 2.3, we have

$$
\begin{aligned}
d\left(g(x), g\left(x^{*}\right)\right)+d\left(g(y), g\left(y^{*}\right)\right) & =d\left(F(x, y), F\left(x^{*}, y^{*}\right)\right)+d\left(F(y, x), F\left(y^{*}, x^{*}\right)\right) \\
& <d\left(g(x), g\left(x^{*}\right)\right)+d\left(g(y), g\left(y^{*}\right)\right)
\end{aligned}
$$

which is a contradiction. Therefore, we have $g(x)=g\left(x^{*}\right)$ and $g(y)=g\left(y^{*}\right)$.

Second Case. Suppose that $(F(x, y), F(y, x))$ and $\left(F\left(x^{*}, y^{*}\right), F\left(y^{*}, x^{*}\right)\right)$ are not comparable. By assumption there exists $(a, b) \in X^{2}$ such that $(F(a, b), F(b, a))$ is comparable to both $(F(x, y), F(y, x))$ and $\left(F\left(x^{*}, y^{*}\right), F\left(y^{*}, x^{*}\right)\right)$.

Setting $a=a_{0}, b=b_{0}$, as in the proof of Theorem 2.4, we define the sequences $\left\{g\left(a_{n}\right)\right\}$ and $\left\{g\left(b_{n}\right)\right\}$ as follows:

$$
g\left(a_{n+1}\right)=F\left(a_{n}, b_{n}\right), \quad g\left(b_{n+1}\right)=F\left(b_{n}, a_{n}\right) \quad \forall n=0,1,2, \ldots
$$

Since $(F(x, y), F(y, x))=(g(x), g(y))$ and $(F(a, b), F(b, a))=\left(g\left(a_{1}\right), g\left(b_{1}\right)\right)$ are comparable, we may assume without loss of generality that $g(x)<g\left(a_{1}\right)$ and $g(y) \geq g\left(b_{1}\right)$. Inductively, we observe that $g(x)<g\left(a_{n}\right)$ and $g(y) \geq g\left(b_{n}\right)$ for all $n \geq 1$. Thus, by Lemma 2.3, we get that

$$
\begin{aligned}
d\left(g(x), g\left(a_{n+1}\right)\right)+d\left(g(y), g\left(b_{n+1}\right)\right) & =d\left(F(x, y), F\left(a_{n}, b_{n}\right)\right)+d\left(F(y, x), F\left(b_{n}, a_{n}\right)\right) \\
& <d\left(g(x), g\left(a_{n}\right)\right)+d\left(g(y), g\left(b_{n}\right)\right) .
\end{aligned}
$$

Set $\lambda_{n}=d\left(g(x), g\left(a_{n}\right)\right)+d\left(g(y), g\left(b_{n}\right)\right)$. Hence, for each $n \geq 0$

$$
\lambda_{n+1}<\lambda_{n} .
$$


Therefore, the sequence $\left\{\lambda_{n}\right\}$ is decreasing and bounded below by 0 . Hence, it converges to some $L \geq 0$. Assume that $L>0$. Then, for some positive integer $k$, we have for all $n \geq k$

$$
\varepsilon \leq \frac{\lambda_{n}}{2}=\frac{1}{2}\left[d\left(g(x), g\left(a_{n}\right)\right)+d\left(g(y), g\left(b_{n}\right)\right)\right]<\varepsilon+\delta(\varepsilon),
$$

where we choose $\varepsilon=L / 2$. In particular, for $n=k$

$$
\varepsilon \leq \frac{\lambda_{k}}{2}=\frac{1}{2}\left[d\left(g(x), g\left(a_{k}\right)\right)+d\left(g(y), g\left(b_{k}\right)\right)\right]<\varepsilon+\delta(\varepsilon) .
$$

Having in mind (3.10) and the fact that $F$ is a weak generalized $g$-Meir-Keeler contraction, we get that

$$
\frac{1}{2}\left[d\left(F(x, y), F\left(a_{k}, b_{k}\right)\right)+d\left(F(y, x), F\left(b_{k}, a_{k}\right)\right)\right]<\varepsilon,
$$

which is equivalent to

$$
\frac{1}{2}\left[d\left(g(x), g\left(a_{k+1}\right)\right)+d\left(g(y), g\left(b_{k+1}\right)\right)\right]<\varepsilon .
$$

Hence, we obtain

$$
\frac{\lambda_{k+1}}{2}<\varepsilon
$$

which contradicts (3.9) for $n=k+1$. Thus, we deduce that $L=0$, that is:

$$
\lim _{n \rightarrow \infty} d\left(g(x), g\left(a_{n}\right)\right)+d\left(g(y), g\left(b_{n}\right)\right)=0 .
$$

In a similar manner, we can show that

$$
\lim _{n \rightarrow \infty} d\left(g\left(x^{*}\right), g\left(a_{n}\right)\right)+d\left(g\left(y^{*}\right), g\left(b_{n}\right)\right)=0 .
$$

By the triangle inequality, we have

$$
\begin{aligned}
0 \leq d\left(g(x), g\left(x^{*}\right)\right) & \leq d\left(g(x), g\left(a_{n}\right)\right)+d\left(g\left(a_{n}\right), g\left(x^{*}\right)\right) \\
& \longrightarrow 0 \text { as } n \longrightarrow \infty \\
0 \leq d\left(g(y), g\left(y^{*}\right)\right) & \leq d\left(g(y), g\left(b_{n}\right)\right)+d\left(g\left(b_{n}\right), g\left(y^{*}\right)\right) \\
& \longrightarrow 0 \text { as } n \longrightarrow \infty .
\end{aligned}
$$


Combining all observations mentioned previously, we get $d\left(g\left(x^{*}\right), g(x)\right)=0$ and $d\left(g\left(y^{*}\right)\right.$, $g(y))=0$. Hence, we have

$$
g(x)=g\left(x^{*}\right), \quad g(y)=g\left(y^{*}\right) .
$$

Last, we show that $g(x)=x$ and $g(y)=y$. Let $g(x)=u$ and $g(y)=v$. By the commutativity of $F$ and $g$ and the fact that $g(x)=F(x, y)$ and $F(y, x)=g(y)$, we have

$$
\begin{aligned}
& g(u)=g(g(x))=g(F(x, y))=F(g(x), g(y))=F(u, v), \\
& g(v)=g(g(y))=g(F(y, x))=F(g(y), g(x))=F(v, u) .
\end{aligned}
$$

Thus, $(u, v)$ is a coupled coincidence point of $F$ and $g$. However, according to (3.17), we must have

$$
g(x)=g(u), \quad g(y)=g(v) .
$$

Hence, we deduce

$$
u=g(u)=F(u, v), \quad v=g(v)=F(v, u),
$$

that is, the pair $(u, v)$ is the coupled common fixed point of $F$ and $g$.

We claim that $(u, v)$ is the unique coupled common fixed point of $F$ and $g$. Assume that $(z, w)$ is another coupled common fixed point of $F$ and $g$. But,

$$
u=g(u)=g(z)=z, \quad v=g(v)=g(w)=w
$$

follows from (3.17).

The particular case in which $g$ is the identity function can be given as a corollary.

Corollary 3.2. In addition to the hypotheses of Corollary 2.7, assume that for all $(x, y),\left(x^{*}, y^{*}\right) \in X^{2}$, there exists $(a, b) \in X^{2}$ such that $(F(a, b), F(b, a))$ is comparable to both $(F(x, y), F(y, x))$ and $\left(F\left(x^{*}, y^{*}\right), F\left(y^{*}, x^{*}\right)\right)$. Then, $F$ has a unique coupled fixed point.

\section{Application}

In this section we give an application of the main theorems relevant to weak generalized $g$-Meir-Keeler type contractions. For this, we need the following theorem.

Theorem 4.1. Let $(X, \leq)$ be a partially ordered set, and suppose that there is a metric $d$ on $X$. Let $F: X^{2} \rightarrow X$ and let $g: X \rightarrow X$ be two given mappings. Let also $\phi:[0, \infty) \rightarrow[0, \infty)$ be a function satisfying the following:

(i) $\phi(0)=0$ and $\phi(t)>0$ for all $t>0$,

(ii) $\phi$ is nondecreasing and right continuous, 
(iii) for any $\varepsilon>0$ there exists $\delta(\varepsilon)>0$ such that for all $x, y, u, v \in X$ with $g(x) \leq g(u)$ and $g(y) \geq g(v)$

$$
\begin{aligned}
\varepsilon & \leq \phi\left(\frac{1}{2}[d(g(x), g(u))+d(g(y), g(v))]\right)<\varepsilon+\delta(\varepsilon) \\
& \Longrightarrow \phi\left(\frac{1}{2}[d(F(x, y), F(u, v))+d(F(y, x), F(v, u))]\right)<\varepsilon
\end{aligned}
$$

Then the mapping $F$ is a weak generalized g-Meir-Keeler contraction.

Proof. By the condition (i) $\phi(\varepsilon)>0$ for any $\varepsilon>0$. Then according to (iii), for $\phi(\varepsilon)>0$ there exists $\gamma>0$ such that, for all $x, y, u, v \in X$ with $g(x) \leq g(u)$ and $g(y) \geq g(v)$

$$
\begin{aligned}
\phi(\varepsilon) & \leq \phi\left(\frac{1}{2}[d(g(x), g(u))+d(g(y), g(v))]\right)<\phi(\varepsilon)+\gamma \\
& \Longrightarrow \phi\left(\frac{1}{2}[d(F(x, y), F(u, v))+d(F(y, x), F(v, u))]\right)<\phi(\varepsilon) .
\end{aligned}
$$

Since $\phi$ is right continuous, so there exists $\delta>0$ such that

$$
\phi(\varepsilon+\delta)<\phi(\varepsilon)+\gamma
$$

Now, fix $x, y, u, v \in X$ satisfying $g(x) \leq g(u), g(y) \geq g(v)$ and

$$
\varepsilon \leq \frac{1}{2}[d(g(x), g(u))+d(g(y), g(v))]<\varepsilon+\delta .
$$

Since $\phi$ is nondecreasing, so we have

$$
\phi(\varepsilon) \leq \phi\left(\frac{1}{2}[d(g(x), g(u))+d(g(y), g(v))]\right) \leq \phi(\varepsilon+\delta)<\phi(\varepsilon)+\gamma .
$$

From (4.2),

$$
\phi\left(\frac{1}{2}[d(F(x, y), F(u, v))+d(F(y, x), F(v, u))]\right)<\phi(\varepsilon)
$$

Regarding the nondecreasing behavior of the function $\phi$, we get

$$
\frac{1}{2}[d(F(x, y), F(u, v))+d(F(y, x), F(v, u))]<\varepsilon .
$$

Consequently, $F$ is a weak generalized $g$-Meir-Keeler type contraction.

If $g$ is the identity function, we derive the following special case of the Theorem 4.1. 
Corollary 4.2. Let $(X, \leq)$ be a partially ordered set, and suppose that there is a metric $d$ on $X$. Let $F: X^{2} \rightarrow X$. Let also $\phi:[0, \infty) \rightarrow[0, \infty)$ be a function satisfying the following:

(i) $\phi(0)=0$ and $\phi(t)>0$ for all $t>0$,

(ii) $\phi$ is nondecreasing and right continuous,

(iii) for any $\varepsilon>0$ there exists $\delta(\varepsilon)>0$ such that for all $x, y, u, v \in X$ with $x \leq u$ and $y \geq v$,

$$
\begin{aligned}
\varepsilon & \leq \phi\left(\frac{1}{2}[d(x, u)+d(y, v)]\right)<\varepsilon+\delta(\varepsilon) \\
& \Longrightarrow \phi\left(\frac{1}{2}[d(F(x, y), F(u, v))+d(F(y, x), F(v, u))]\right)<\varepsilon .
\end{aligned}
$$

Then, the mapping $F$ is a weak Meir-Keeler contraction.

The subsequent results are particular cases of Theorems 2.4 and 4.1.

Corollary 4.3. Let $(X, \leq)$ be a partially ordered set, and suppose that there is a metric $d$ on $X$ such that $(X, d)$ is a complete metric space. Let $F: X^{2} \rightarrow X$ and let $g: X \rightarrow X$ be two given mappings such that $F\left(X^{2}\right) \subseteq g(X), g$ is continuous and commutes with $F$. Also, suppose the following conditions:

(i) $F$ is continuous,

(ii) F has the mixed strict g-monotone property,

(iii) for any $\varepsilon>0$, there exists $\delta(\varepsilon)>0$ such that for all $x, y, u, v \in X$ satisfying $g(x) \leq g(u)$ and $g(y) \geq g(v)$,

$$
\begin{aligned}
\varepsilon & \leq \int_{0}^{(1 / 2)[d(g(x), g(u))+d(g(y), g(v))]} \phi(s) d s<\varepsilon+\delta(\varepsilon) \\
\Longrightarrow & \int_{0}^{(1 / 2)[d(F(x, y), F(u, v))+d(F(y, x), F(v, u))]} \phi(s) d s<\varepsilon
\end{aligned}
$$

where $\phi:[0, \infty) \rightarrow[0, \infty)$ is locally integrable and for all $t>0$

$$
\int_{0}^{t} \phi(s) d s>0
$$

(iv) there exist $x_{0}, y_{0} \in X$ such that

$$
g\left(x_{0}\right)<F\left(x_{0}, y_{0}\right), \quad g\left(y_{0}\right) \geq F\left(y_{0}, x_{0}\right) .
$$

Then, $F$ and $g$ have a coupled coincidence point; that is, there exist $x, y \in X$ such that

$$
F(x, y)=g(x), \quad F(y, x)=g(y) .
$$


If, in addition, for all $(x, y),\left(x^{*}, y^{*}\right) \in X^{2}$, there exists $(a, b) \in X^{2}$ such that $(F(a, b), F(b, a))$ is comparable to both $(F(x, y), F(y, x))$ and $\left(F\left(x^{*}, y^{*}\right), F\left(y^{*}, x^{*}\right)\right)$, then $F$ and $g$ have a unique common coupled fixed point.

Corollary 4.4. Let $(X, \leq)$ be a partially ordered set, and suppose that there is a metric $d$ on $X$ such that $(X, d)$ is a complete metric space. Let $F: X^{2} \rightarrow X$ be a mapping satisfying the following conditions:

(i) $F$ is continuous,

(ii) F has the mixed strict monotone property,

(iii) for any $\varepsilon>0$ there exists $\delta(\varepsilon)>0$ such that for all $x, y, u, v \in X$ satisfying $x \leq u$ and $y \geq v$,

$$
\begin{aligned}
\varepsilon & \leq \int_{0}^{(1 / 2)[d(x, u)+d(y, v)]} \phi(s) d s<\varepsilon+\delta(\varepsilon) \\
& \Longrightarrow \int_{0}^{(1 / 2)[d(F(x, y), F(u, v))+d(F(y, x), F(v, u))]} \phi(s) d s<\varepsilon
\end{aligned}
$$

where $\phi:[0, \infty) \rightarrow[0, \infty)$ is locally integrable and for all $t>0$

$$
\int_{0}^{t} \phi(s) d s>0
$$

(iv) there exist $x_{0}, y_{0} \in X$ such that

$$
x_{0}<F\left(x_{0}, y_{0}\right), \quad y_{0} \geq F\left(y_{0}, x_{0}\right) .
$$

Then $F$ has a coupled fixed point; that is, there exist $x, y \in X$ such that

$$
F(x, y)=x, \quad F(y, x)=y
$$

If, in addition, for all $(x, y),\left(x^{*}, y^{*}\right) \in X^{2}$, there exists $(a, b) \in X^{2}$ such that $(F(a, b), F(b, a))$ is comparable to both $(F(x, y), F(y, x))$ and $\left(F\left(x^{*}, y^{*}\right), F\left(y^{*}, x^{*}\right)\right)$, then $F$ has a unique coupled fixed point.

\section{References}

[1] I. Meznik, "Banach fixed point theorem and the stability of the market," in Proceedings of the International Conference on Mathematics Education into the 21st Century Project, 2003.

[2] A. Cataldo, E. A. Lee, X. Liu, E. D. Matsikoudis, and H. Zheng, "A constructive fixed point theorem and the feedback semantics of timed systems," Tech. Rep. UCB/EECS-2006, EECS Department, University of California, Berkeley, Calif, USA, 2006.

[3] T. Abdeljawad, H. Aydi, and E. Karapinar, "Coupled fixed points for Meir-Keeler contractions in ordered partial metric spaces," Mathematical Problems in Engineering. In press.

[4] J. Harjani, B. López, and K. Sadarangani, "Fixed point theorems for mixed monotone operators and applications to integral equations," Nonlinear Analysis. Theory, Methods E Applications, vol. 74, no. 5, pp. 1749-1760, 2011. 
[5] J. Caballero, J. Harjani, and K. Sadarangani, "Positive solutions for a class of singular fractional boundary value problems," Computers \& Mathematics with Applications, vol. 62, no. 3, pp. 1325-1332, 2011.

[6] A. Noumsi, S. Derrien, and P. Quinton, "Acceleration of a content based image retrieval application on the RDISK cluster," in Proceedings of the IEEE International Parallel and Distributed Processing Symposium, April 2006.

[7] A. Hyvärinen, "Fast and robust fixed-point algorithms for independent component analysis," IEEE Transactions on Neural Networks, vol. 10, no. 3, pp. 626-634, 1999.

[8] D. P. Mandic, J. A. Chambers, and M. M. Bozic, "On global asymptotic stability of fully connected recurrent neural networks," in Proceedings of the International Conference on Acoustics Speech and Signal Processing (ICASSP '00), pp. 3406-3409, 2000.

[9] M. Turinici, "Abstract comparison principles and multivariable Gronwall-Bellman inequalities," Journal of Mathematical Analysis and Applications, vol. 117, no. 1, pp. 100-127, 1986.

[10] A. C. M. Ran and M. C. B. Reurings, "A fixed point theorem in partially ordered sets and some applications to matrix equations," Proceedings of the American Mathematical Society, vol. 132, no. 5, pp. 1435-1443, 2004.

[11] R. P. Agarwal, M. A. El-Gebeily, and D. O’Regan, "Generalized contractions in partially ordered metric spaces," Applicable Analysis, vol. 87, no. 1, pp. 109-116, 2008.

[12] T. Gnana Bhaskar and V. Lakshmikantham, "Fixed point theorems in partially ordered metric spaces and applications," Nonlinear Analysis. Theory, Methods \& Applications, vol. 65, no. 7, pp. 1379-1393, 2006.

[13] M. Jleli and B. Samet, “On positive solutions for a class of singular nonlinear fractional differential equations," Boundary Value Problems. In press.

[14] V. Berinde and M. Borcut, "Tripled fixed point theorems for contractive type mappings in partially ordered metric spaces," Nonlinear Analysis. Theory, Methods E Applications, vol. 74, no. 15, pp. 48894897, 2011.

[15] V. Berinde, "Coupled fixed point theorems for generalized symmetric Meir-Keeler contractions in ordered metric spaces," Fixed Point Theory and Applications. In press.

[16] E. Karapınar, "Couple fixed point on cone metric spaces," Gazi University Journal of Science, vol. 24, pp. 51-58, 2011.

[17] E. Karapinar, "Couple fixed point theorems for nonlinear contractions in cone metric spaces," Computers \& Mathematics with Applications. An International Journal, vol. 59, no. 12, pp. 3656-3668, 2010.

[18] E. Karapinar, "Weak $\varphi$-contraction on partial metric spaces and existence of fixed points in partially ordered sets," Mathematica Æterna, vol. 1, no. 3-4, pp. 237-244, 2011.

[19] V. Lakshmikantham and L. Ćirić, "Coupled fixed point theorems for nonlinear contractions in partially ordered metric spaces," Nonlinear Analysis. Theory, Methods E Applications, vol. 70, no. 12, pp. 4341-4349, 2009.

[20] N. V. Luong and N. X. Thuan, "Coupled fixed points in partially ordered metric spaces and application," Nonlinear Analysis. Theory, Methods \& Applications, vol. 74, no. 3, pp. 983-992, 2011.

[21] H. K. Nashine and B. Samet, "Fixed point results for mappings satisfying $(\psi, \varphi)$-weakly contractive condition in partially ordered metric spaces," Nonlinear Analysis. Theory, Methods E Applications, vol. 74, no. 6, pp. 2201-2209, 2011.

[22] J. J. Nieto and R. Rodríguez-López, "Contractive mapping theorems in partially ordered sets and applications to ordinary differential equations," Order, vol. 22, no. 3, pp. 223-239, 2005.

[23] B. Samet, "Coupled fixed point theorems for a generalized Meir-Keeler contraction in partially ordered metric spaces," Nonlinear Analysis. Theory, Methods E Applications, vol. 72, no. 12, pp. 45084517, 2010.

[24] B. Samet and C. Vetro, "Coupled fixed point, F-invariant set and fixed point of N-order," Annals of Functional Analysis, vol. 1, no. 2, pp. 46-56, 2010.

[25] W. Shatanawi, B. Samet, and M. Abbas, "Coupled fixed point theorems for mixed monotone mappings in ordered partial metric spaces," Mathematical and Computer Modelling, vol. 55, pp. 680687, 2012.

[26] M. E. Gordji, Y. J. Cho, S. Ghods, M. Ghods, and M. H. Dehkordi, “Coupled fixed point theorems for contractions in partially ordered metric spaces and applications," Mathematical Problems in Engineering. In press. 


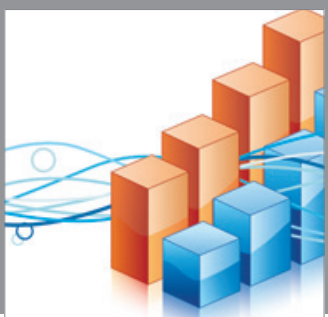

Advances in

Operations Research

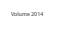

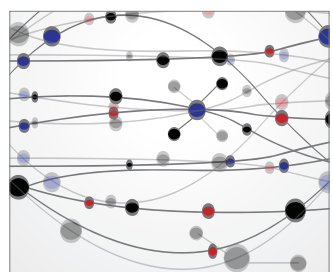

\section{The Scientific} World Journal
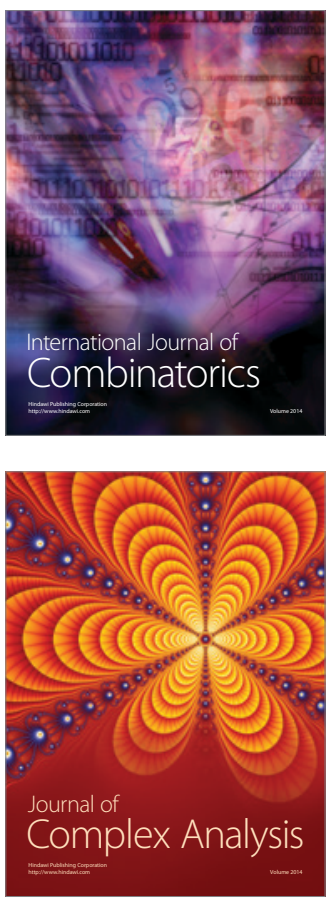

International Journal of

Mathematics and

Mathematical

Sciences
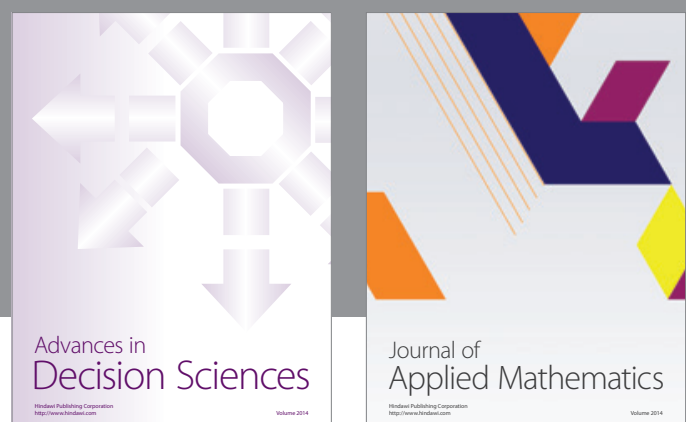

Journal of

Applied Mathematics
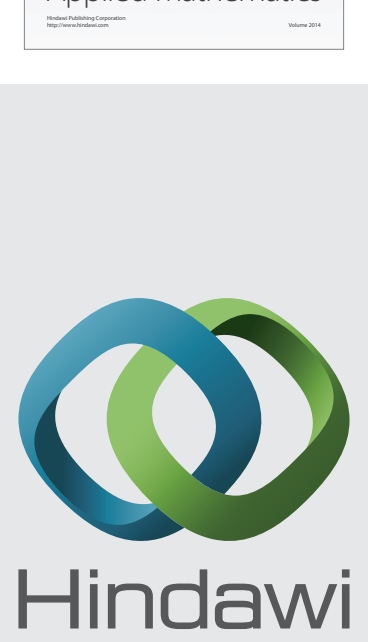

Submit your manuscripts at http://www.hindawi.com
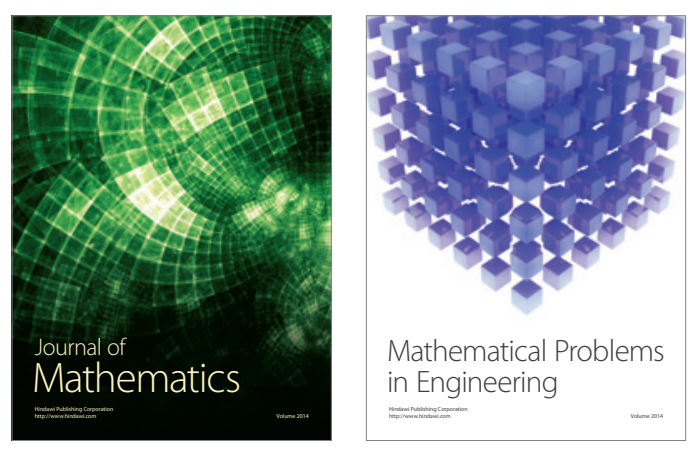

Mathematical Problems in Engineering
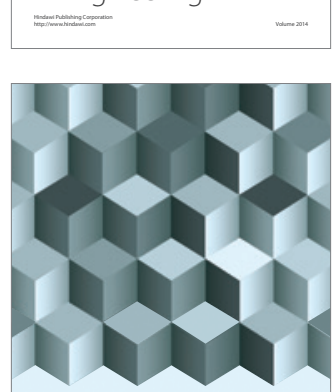

Journal of

Function Spaces
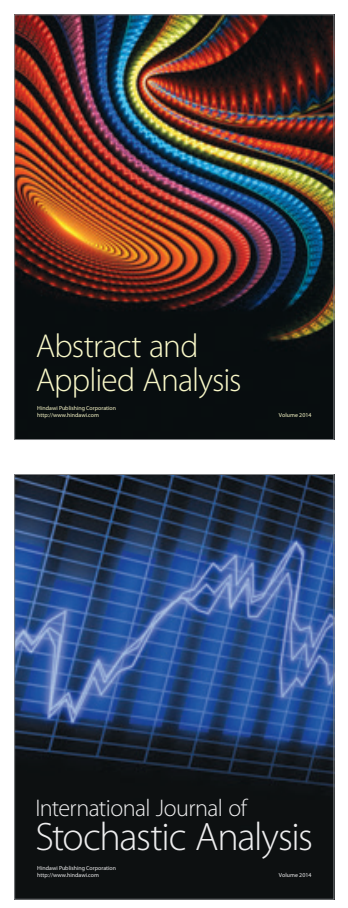

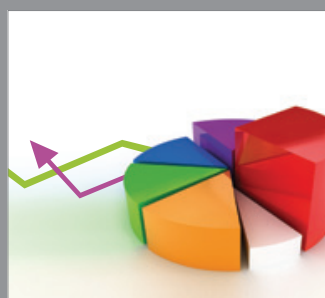

ournal of

Probability and Statistics

Promensencen
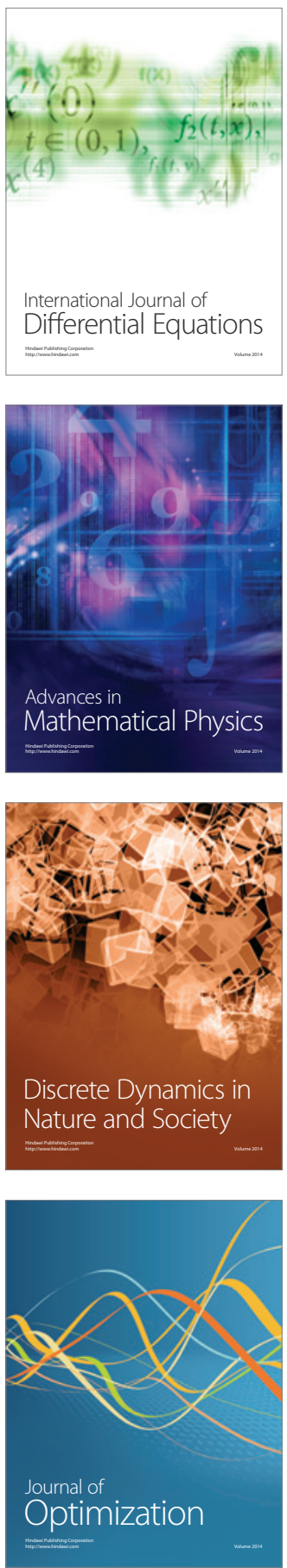